\title{
STABILITY INDICATING RP-HPLC METHOD FOR SIMULTANEOUS DETERMINATION OF POTENTIAL IMPURITIES OF SUMATRIPTAN AND NAPROXEN SODIUM IN FIXED DOSE COMBINATION
}

\author{
S. P. Vittal ${ }^{1}$, Sumathi V. Rao ${ }^{1}$ and K. Ramakrishna ${ }^{2, *}$ \\ ${ }^{1}$ APL Research Centre (A division of Aurobindo Pharma Limited), Hyderabad-500072, \\ Telangana, India. \\ ${ }^{2}$ Department of Chemistry, Institute of Science, GITAM (Deemed to be University), \\ Visakhapatnam-530 045. A P, India \\ *E-mail: karipeddirk@gmail.com
}

\begin{abstract}
The current publication describes about development, optimization and validation of simultaneous estimation of impurities present in Sumatriptan and Naproxen sodium tablets using High-Performance Liquid Chromatography (HPLC). Perchlorate buffer (contains $1.0 \mathrm{~mL} / \mathrm{L}$ of Perchloric acid and $4 \mathrm{~g} / \mathrm{L}$ of sodium perchlorate) is used as Elution phase $\sim$ A along with acetonitrile as Elution phase $\sim$ B. Step gradient mode elution technique is opted with a flow rate of $1.0 \mathrm{~mL} / \mathrm{min}$ with ACE $5 \mathrm{C} 18 \mathrm{PFP} 5 \mu, 250 \mathrm{x} 4.6 \mathrm{~mm}$ column. All the probable impurities are well resolved at a satisfactory level, showing resolution more than 1.2 in sensitive robustness conditions for closely eluting peaks. The projected method is appropriate for quantification of SUM and NAP related known and unknown impurities that originate from the life cycle of the combination drug product. Selected quantification wavelength of $230 \mathrm{~nm}$ is found suitable for quantification purpose. Impurities show satisfactory responses and did not find any placebo interference at this working wavelength. Linearity data depicts a linear relationship with a coefficient of correlation greater than 0.99. The projected method is validated as per compendia recommendation as mentioned in ICH. The developed method is highly useful for quantification of impurities in Sumatriptan and Naproxen sodium tablets in a single method.

Keywords: Sumatriptan, Naproxen Sodium, Validation, Stability Indicating, Fixed-dose Combination, Impurities.

(C) RASĀYAN. All rights reserved
\end{abstract}

\section{INTRODUCTION}

Sumatriptan and Naproxen sodium tablets is a combination drug product used for the treatment of migraine head ache attacks in adults. TREXIMET tablets have a label claim of $85 \mathrm{mg}$ Sumatriptan which is equivalent to $119 \mathrm{mg}$ of Sumatriptan succinate (SUM) and $500 \mathrm{mg}$ of Naproxen sodium (NAP). SUM is used for the management of migraine headache. NAP belongs to the arylacetic acid group of nonsteroidal anti-inflammatory drugs (NSAIDs). It is an anti-inflammatory medicine. It also reduces stiffness caused by bursitis, arthritis and gout attacks ${ }^{1-5}$.

SUM is a white to off-white powder, which is freely soluble in aqueous solvents like water. The chemical name is "3-[2-(dimethylamino)ethyl]-N-methyl-1H-indole-5-methanesulfonamide-butanedioic acid". The empirical formula is $\mathrm{C}_{14} \mathrm{H}_{21} \mathrm{~N}_{3} \mathrm{O}_{2} \mathrm{~S} \bullet \mathrm{C}_{4} \mathrm{H}_{6} \mathrm{O}_{4}$, with a molecular weight of 413.5 (Fig.-1). NAP is a white-tocreamy white crystalline solid, freely soluble in water at neutral $\mathrm{pH}$. The chemical name is"(S)-6methoxy-a-methyl-2-naphthaleneacetic acid, sodium salt". The empirical formula is $\mathrm{C}_{14} \mathrm{H}_{13} \mathrm{NaO}_{3}$, representing a molecular weight of 252.23(Fig.-2).

A meticulous review on literature reveals that few testing procedures are available using HPTLC ${ }^{6}$, Spectrophotometric $^{7-8}$ and $\mathrm{LC} \mathrm{MS}^{9}$ techniques for quantification of SUM and NAP in different formulation products. Some methods are also available for simultaneous estimation of SUM and NAP

Rasayan J. Chem., 12(3), 1601-1612(2019)

http://dx.doi.org/10.31788/RJC.2019.1235183

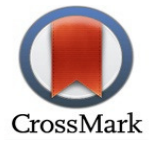


RASĀYAN J. Chem.

Vol. 12 | No. 3 |1601 - 1612| July - September | 2019

using HPLC ${ }^{10-12}$ and UPLC ${ }^{13}$ techniques. Few methods are published to determine either SUM or NAP impurities in fixed-dose combination ${ }^{14-16}$.

Few reports are available for quantification of SUM and NAP impurities in SUM and NAP combination by UPLC method ${ }^{17}$. The reported publication confirms the estimation of impurities in the presence of SUM and NAP drug substances only but not in the drug product. The specificity of the unknowns generated during the life cycle of the product cannot be predicted completely in the published method. Hence considering the above facts a common HPLC method was developed for simultaneous quantification of impurities for this combination drug product and subsequently validated as per compendia requirement ${ }^{18-22}$.<smiles>CNS(=O)(=O)Cc1ccc2[nH]cc(CCN(C)C)c2c1</smiles>

Fig.-1: SUM Structure<smiles>CNS(=O)(=O)Cc1ccc2[nH]cc(CCN)c2c1</smiles>

SUM impurity 1" "[3-(2-Aminoethyl)-1H-Indol-5-YL]-Nmethylmethane sulfonamide"<smiles>CNCCc1c[nH]c2ccc(CS(=O)(=O)NC)cc12</smiles>

SUM impurity 3 “[3-[2-(Methyl amino) Ethyl]-1H-Indol5-YL]-N-Methyl methane sulfonamide (OR) [3-[2-(methyl amino) Ethyl]-1H-Indol-5-YL]-N-methyl methane sulfonamide"<smiles>CNS(=O)(=O)Cc1ccc2[nH]c(Cc3ccc4[nH]cc(CCN(C)C)c4c3)c(CCN(C)C)c2c1</smiles>

SUM impurity 5"Sumatriptan-2,5-Dimer:[3-[2(Dimethylamino)Ethyl]-2-[[3-[2-(Dimethyl amino)ethyl]1H-indol-5-YL]methyl]-1H-indol-5-YL]-Nmethylmethane sulfonamide"<smiles>COc1ccc2cc(C(C)C(C)C)ccc2c1</smiles>

Fig.-2: NAP Structure<smiles>CNS(=O)(=O)Cc1ccc2c(c1)c(CCN(C)C)cn2CO</smiles>

SUM impurity 2“" [3-[2-(Dimethylamino) ethyl]-1(hydroxymethyl)-1H-Indol-5-YL]-NMethylmethanesulfonamide"<smiles></smiles>

SUM impurity 4"[3-[2-(Dimethyl Amino N-Oxide) Ethyl]-1H-Indol-5-YL]-N-methyl methane sulfonamide (OR) [3-[-2(Dimethyl Amino-N-Oxide) Ethyl]-1H-Indol-5-YL]-N-methyl methane sulfonamide"<smiles></smiles>

SUM impurity 6“"Sumatriptan-1,5-Dimer:[3-[2(Dimethylamino) Ethyl]-1-[[3-[2-(DimethylAmino) Ethyl] -1h-Indol-5-YL]methyl]-1H-indol-5-YL]-Nmethylsulfonamide"

Fig.-3: SUM Related Impurities

Since SUM and its by-products (impurities) are polar in nature, it is difficult to develop a method on HPLC using conventional buffers generally used in liquid chromatography. Hence the choice is to 
develop a method using High-performance liquid chromatography (HPLC) adopting ion pair buffers is the modest way to retain polar peaks followed by separation of potential impurities of different polarity index.

This paper presents development strategy and validation activity for the impurities that may be formed from SUM and NAP respectively. Forced degradation studies reveal that all potential impurities that are formed during different stress conditions are well separated. Hence developed procedure can be claimed as stability demonstrating method and meets the ICH requirement parameters. The possible impurities that are formed from the SUM are SUM impurity 1, SUM impurity 2, SUM impurity 3, SUM impurity 4, SUM impurity 5 and SUM impurity 6 (Fig.-3). For NAP is NAP impurity 1, NAP impurity 2, NAP impurity 3, NAP impurity 4, NAP impurity 5 and NAP impurity 6 (Fig.-4).<smiles>CC(C(=O)O)c1ccc2cc(O)ccc2c1</smiles>

NAP impurity 1“(2S)-2-(6-Hydroxy naphthalene-2-YL) propanoic acid"<smiles>COc1ccc2cc(C(C)=O)ccc2c1</smiles>

NAP impurity 3"1-(6-Methoxy naphthalene-2-YL) ethanone"<smiles>COc1ccc2cc(C(C)C(C)=O)ccc2c1</smiles>

NAP impurity 5 "Methyl (2S)-2-(6-Methoxy naphthalene$2-\mathrm{YL})$ propanoate"<smiles>COc1ccc2cc(C(C)O)ccc2c1</smiles>

NAP impurity 2“(1RS)-1-(6-Methoxy naphthalene-2YL) ethanol"<smiles>COc1ccc2ccccc2c1</smiles>

NAP impurity 4"2-Methoxy naphthalene"<smiles>CCc1ccc2cc(OC)ccc2c1</smiles>

Fig.-4: Naproxen Sodium Related Impurities

NAP impurity 6"2-Ethyl-6-Methoxy naphthalene"

\section{EXPERIMENTAL}

\section{Instruments}

HPLC system of waters alliance make is used, which contains quaternary gradient pump system, Auto sampler, column oven compartment and PDA detector for detection. Empower 2 software was used as interphase. The column used was ACE 5 C18 PFP, $5 \mu, 250 \mathrm{~mm} \times 4.6 \mathrm{~mm}$.

\section{Chemicals}

Sumatriptan succinate standard, Naproxen sodium standard, SUM and NAP impurities, Sumatriptan and Naproxen sodium tablets (TREXIMET tablets) were funded by Aurobindo Pharma Limited. HPLC grade Acetonitrile and remaining chemicals like Monobasic Potassium phosphate, Sodium Perchlorate monohydrate, Perchloric acid $(\approx 70 \%)$, and Orthophosphoric acid $(\approx 88 \%)$ of analytical reagent grade chemicals were taken from Merck Millipore. Water for preparation was taken from Evoqua water purifier.

\section{Method Development Along with Optimization of the Method}

The current paper describes strategic method development work which is capable enough to separate all possible potential impurities that appear during the process and different degradation conditions. No compendial methods being cited in any pharmacopoeia for simultaneous determination of impurities in 
this drug product combination. Polarity index of SUM shows highly polar in nature when compared to NAP. It is difficult to retain or separate polar eluents in liquid chromatography. The choice of separation for these impurities is likely dependant on a selection of ion pairs used in Elution phase preparation or use aqua-based technology columns. Using ion pair reagent is a better choice to separate polar impurities, since these reagents are widely available with different chemical properties. Hence ion-pair reagents have been chosen for buffer preparation. Initially, trials were initiated with a mixture of sodium Perchlorate monohydrate and Perchloric acid ion pair buffer. The reason to select this ion pair is due to low viscous nature, easy to handle and compatible to use for gradient elution. Since this FDC product contains different polarity properties for potential impurities, it is mandated to use gradient elution mode to get a shorter run time. Perchlorate buffer (contains $1.0 \mathrm{~mL} / \mathrm{L}$ of perchloric acid and $4 \mathrm{~g} / \mathrm{L}$ of sodium perchlorate) as Elution phase $\sim \mathrm{A}$ along with acetonitrile as Elution phase $\mathrm{B}$ is used with step gradient elution. In all trials, $1.0 \mathrm{~mL}$ per minute flow rate shows promising separations and hence same the flow was kept in an optimized method.

The column used in chromatography for trial purpose is ACE PFP C18, $5 \mu, 250 \times 4.6 \mathrm{~mm}$. The reason to select this column is ACE PFP C18 is a unique column which is a combination of C18 \& PFP mechanisms and is having more advantage than either phase alone for separation. Since SUM and NAP contain structurally similar impurities which can elute very close to respective drug components, an advantage can be taken in terms of selectivity to get proper resolution by taking this unique column phase. The same column was finalized for chromatography.

Trials have been taken using a proposed diluent which contains a mixture of $\mathrm{pH} 3.6$ phosphate buffer along with acetonitrile in the proportion of 55:45. In this diluent, all impurities were well dissolved and found stable in the proposed diluent. To check the individual impurity retention times, all impurity mixture is prepared at a proposed specification limit assigned to each impurity and injected using a PDA detector. Impurities related to SUM and NAP shows wavelength maxima at about $230 \mathrm{~nm}$. Hence for quantification for all impurities, a wavelength of $230 \mathrm{~nm}$ is opted. $10 \mu \mathrm{L}$ injection volume showed satisfactory responses to each impurity at the proposed test concentration of $212.5 \mu \mathrm{g} / \mathrm{mL}$ for SUM $1250 \mu \mathrm{g} / \mathrm{mL}$ for NAP. In the finalized test conditions all impurities are well separated with a reproducible area for each impurity.

\section{Finalized Chromatographic Conditions}

Elution phase $\sim \mathrm{A}$ is mixture $4 \mathrm{~g} / \mathrm{L}$ of sodium perchlorate and $1.0 \mathrm{~mL} / \mathrm{L}$ of perchloric acid along with acetonitrile as Elution phase $\sim$ B. Step mode gradient programme Table- 1 with a flow of $1.0 \mathrm{ml} / \mathrm{min}$ opts. The column temperature is kept at $30^{\circ} \mathrm{C}$ with $230 \mathrm{~nm}$ wavelength for detection using $10 \mu \mathrm{L}$ injection volume. The proposed column is ACE PFP C18. $5 \mu, 250 \times 4.6 \mathrm{~mm}$. The diluent is a mixture of $\mathrm{pH} 3.6$ phosphate buffer ( $\mathrm{pH}$ adjusted with dilute phosphoric acid) along with acetonitrile in the proportion 55:45 opts.

Table-1: Step Mode Gradient Programme

\begin{tabular}{cccc}
\hline $\begin{array}{c}\text { Time } \\
\text { (minutes })\end{array}$ & $\begin{array}{c}\text { Flow } \\
(\mathrm{mL})\end{array}$ & \% Elution phase $\sim$ A & \% Elution phase $\mathrm{B}$ \\
\hline 0.0 & 1.0 & 90 & 10 \\
\hline 15.0 & 1.0 & 70 & 30 \\
\hline 25.0 & 1.0 & 60 & 40 \\
\hline 30.0 & 1.0 & 45 & 55 \\
\hline 35.0 & 1.0 & 20 & 80 \\
\hline 40.0 & 1.0 & 20 & 80 \\
\hline 41.0 & 1.0 & 90 & 10 \\
\hline 50.0 & 1.0 & 90 & 10 \\
\hline
\end{tabular}

Retention times of each impurity and Suitability of chromatographic system Values observed in the finalized method mentioned in Table-2.

\section{Standard Solution Preparation}

SUM and NAP standard solutions were prepared at a concentration of 1.07 and $1.25 \mu \mathrm{g} / \mathrm{mL}$ respectively. Standard solutions were prepared using diluent and impurity stock solutions were prepared using $5 \mathrm{~mL}$ of acetonitrile initially followed by further dilution with diluent.

1604 
RASĀYAN J. Chem.

Vol. 12 | No. 3 |1601 - 1612| July - September | 2019

Table-2: Suitability of Chromatographic System Values

\begin{tabular}{ccccc}
\hline $\begin{array}{c}\text { Name of } \\
\text { Drug/Impurity }\end{array}$ & $\begin{array}{c}\text { Retention times in } \\
\text { minutes }\end{array}$ & $\begin{array}{c}\text { USP \# } \\
\text { Resolution }\end{array}$ & $\begin{array}{c}\text { USP \# Tailing } \\
\text { factor }\end{array}$ & $\begin{array}{c}\text { USP \# Theoretical } \\
\text { plates }\end{array}$ \\
\hline SUM Impurity 1 & 10.95 & -- & 0.99 & 66154 \\
\hline SUM Impurity 2 & 11.38 & 2.53 & 1.01 & 74506 \\
\hline SUM Impurity 3 & 11.68 & 1.71 & 1.02 & 72288 \\
\hline SUM & 12.26 & 3.11 & 1.10 & 63289 \\
\hline SUM Impurity 4 & 13.58 & 6.92 & 1.00 & 89746 \\
\hline SUM Impurity 5 & 18.56 & 26.29 & 1.02 & 155302 \\
\hline SUM Impurity 6 & 19.60 & 5.48 & 1.05 & 176898 \\
\hline NAP Impurity 1 & 21.36 & 8.81 & 1.01 & 171997 \\
\hline NAP Impurity 2 & 29.17 & 34.71 & 1.01 & 237571 \\
\hline NAP & 31.45 & 8.84 & 1.09 & 205429 \\
\hline NAP Impurity 3 & 34.05 & 11.36 & 1.03 & 597026 \\
\hline NAP Impurity 4 & 36.64 & 15.87 & 1.00 & 892973 \\
\hline NAP Impurity 5 & 36.93 & 1.88 & 1.04 & 83548 \\
\hline NAP Impurity 6 & 39.77 & 17.16 & 1.02 & 875 \\
\hline
\end{tabular}

\section{Sample Solution Preparation}

Crushed to a fine powder using not less than 10 tablets. Sample powder equivalent to $42.5 \mathrm{mg}$ of Sumatriptan and $250 \mathrm{mg}$ of Naproxen is taken in dry and clean $200 \mathrm{~mL}$ volumetric flask. To this add onethird volume of diluent and exposed to sonication for about 20 minutes. Mix intermittently to get homogeneity of the test solution. After sonication, keep the solution aside to attain room temperature and make up to the volume with diluent and mix thoroughly. Transfer about $15 \mathrm{~mL}$ of sample solution from flask to centrifuge tube and centrifuge for about 5 minutes at $5000 \mathrm{rpm}$. Filter the solution through $0.45 \mu$ syringe filter. Final sample concentration is about 212 and $1250 \mu \mathrm{g} / \mathrm{mL}$ of SUM and NAP respectively. TREXIMET tablets are available in $85 \mathrm{mg}$ strength for Sumatriptan and $500 \mathrm{mg}$ for Naproxen. These tablets were taken up for complete method validation purpose.

\section{Method Validation}

Method validation covered for specificity, stress degradation, Precision for both inter and intraday (ruggedness), method sensitivity for LOD along with LOQ determination, Linearity, range, accuracy and robustness studies as suggested in ICH.

\section{Specificity and Stress Degradation}

Specificity was performed by spiking the impurities in the test sample as per the proposed specification limit as proposed in Table- 3 and loaded into the system.

Table-3. Specification limit of impurities

\begin{tabular}{ccc}
\hline Name of the component & $\begin{array}{c}\text { Specification } \\
\text { Limit in } \%\end{array}$ & $\begin{array}{c}\text { Specification } \\
\text { Limit in } \mu \mathrm{g} / \mathrm{mL}\end{array}$ \\
\hline SUM impurity 1 & 0.2 & 0.43 \\
\hline SUM impurity 2 & 0.5 & 1.06 \\
\hline SUM impurity 3 & 0.5 & 1.06 \\
\hline SUM impurity 4 & 0.5 & 1.06 \\
\hline SUM impurity 5 & 0.5 & 1.06 \\
\hline SUM impurity 6 & 0.2 & 0.43 \\
\hline NAP impurity 1 & 0.1 & 1.25 \\
\hline NAP impurity 2 & 0.1 & 1.25 \\
\hline NAP impurity 3 & 0.1 & 1.25 \\
\hline NAP impurity 4 & 0.1 & 1.25 \\
\hline NAP impurity 5 & 0.1 & 1.25 \\
\hline NAP impurity $~ 6$ & 0.1 & \\
\hline
\end{tabular}


Samples were prepared and stressed under different degradation conditions. For Acidic exposure, the sample was exposed to $1 \mathrm{M} \mathrm{HCl}$ and heated to $85^{\circ} \mathrm{C}$ for about 3 hours. For alkaline degradation, the sample was exposed to $1 \mathrm{M}$ sodium hydroxide and heated to $85^{\circ} \mathrm{C}$ for about 3 hours. Both acid and alkali exposed samples were neutralized before injecting into HPLC. For oxidative stress condition, the sample was added with $5 \% \mathrm{H}_{2} \mathrm{O}_{2}$ and exposed for about 15 minutes. For Thermal stress study, whole tablets were exposed to $105^{\circ} \mathrm{C}$ for about 120 hours and the sample was prepared for testing. For Humidity stress, sample powder is exposed to $90 \% \mathrm{RH}$ at $25^{\circ} \mathrm{C}$ for 120 Hours and later stressed sample was prepared for testing. For Photolytic stress, tablet powder is exposed to 10K Lux for 120 Hours along with UV 200 W.Hr.m ${ }^{-2}$. This stressed sample is loaded into HPLC after test preparation.

\section{Precision}

Sample powder is taken for analysis and prepared six individual test preparations spiked with impurities at the proposed specification level and loaded into HPLC. Observed results were calculated for \% w/w and \% RSD is assessed for each impurity. Similarly, the ruggedness of the experiment was repeated with another lot column, different day and alternative system.

\section{Sensitivity}

LOD along with LOQ values were determined by loading a series of injections ranging from (1 to 150$) \%$ of the proposed specifications. Using impurity stock solutions, precision was performed based on the predicted concentrations derived from the linearity curves.

\section{Linearity and range}

Linearity along with range was demonstrated by loading a series of injections ranging from observed LOQ level of each impurity to $150 \%$ to the proposed specification limit. Slope, coefficient of correlation and Y-intercept were individually calculated for every individual impurity from the linearity curves.

\section{Accuracy}

Impurity stock solution was prepared and accuracy was proved by spiking them to the control sample at proposed LOQ concentration, at 50\%, 100\%, and 150\% level. Based on $\%$ w/w observed results, calculated the accuracy values. Each spiking procedure was done in triplicate preparations.

\section{Solution Stability}

To establish solution stability, standard and sample solutions were periodically injected at room temperature at different time intervals. Values at different time points were extrapolated against initial freshly injected solutions of standard and sample.

\section{Robustness}

Robustness was performed by deliberately changing the proposed methodology and assessed. The flow rate was changed $\pm 10.0 \%(0.9 \mathrm{~mL}$ and $1.1 \mathrm{~mL}$ per minute $)$, temperature $\pm 5^{\circ} \mathrm{C}\left(25^{\circ} \mathrm{C}\right.$ and $\left.35^{\circ} \mathrm{C}\right)$, gradient composition \pm 2 absolute and wavelength $\pm 5 \mathrm{~nm}(225 \mathrm{~nm}$ and $235 \mathrm{~nm})$. In each experiment, one parameter has deliberately changed by keeping the remaining parameters intact.

\section{Specificity and Stress Studies}

\section{RESULTS AND DISCUSSION}

There was no interference observed from diluent and placebo solutions. Degradation data suggests the following behavior in each condition.

\section{Acid Stress Condition}

SUM shows slight increase in SUM impurity-5. NAP undergoes degradation significantly and found NAP impurity 1, NAP impurity 2, NAP impurity 4 and unknown impurities.

\section{Base Stress Condition}

SUM shows slight increase in SUM impurity 4 and NAP found to be stable in base degradation conditions. There are no unknown peaks seen for both SUM and NAP. 
RASĀYAN J. Chem.

Vol. 12 | No. 3 |1601 - 1612| July - September | 2019

\section{Peroxide Stress Condition}

SUM shows an increase in trend for SUM impurity 4 whereas NAP is found stable. There are no unknown peaks seen for both SUM and NAP.

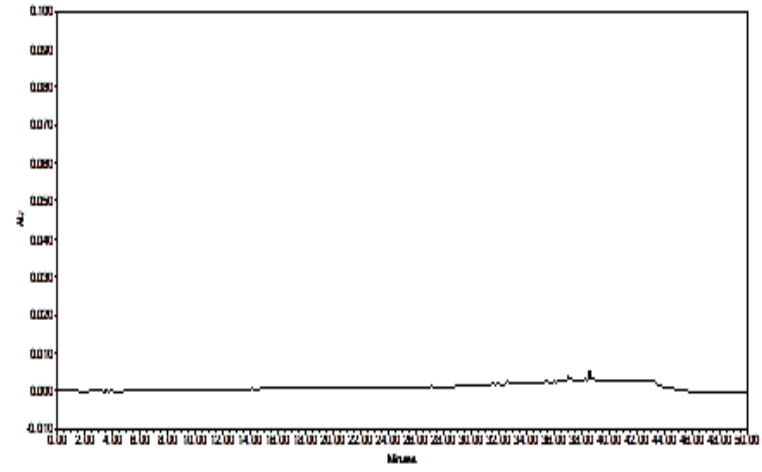

5a. Diluent

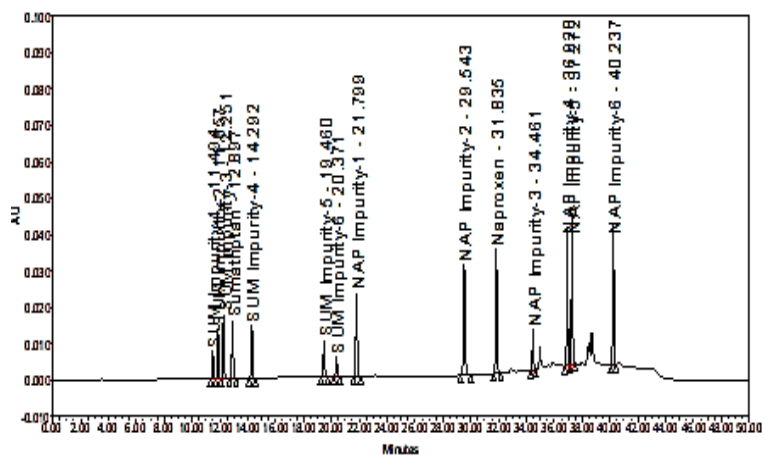

5.c. Standard solution (All impurity mixture)

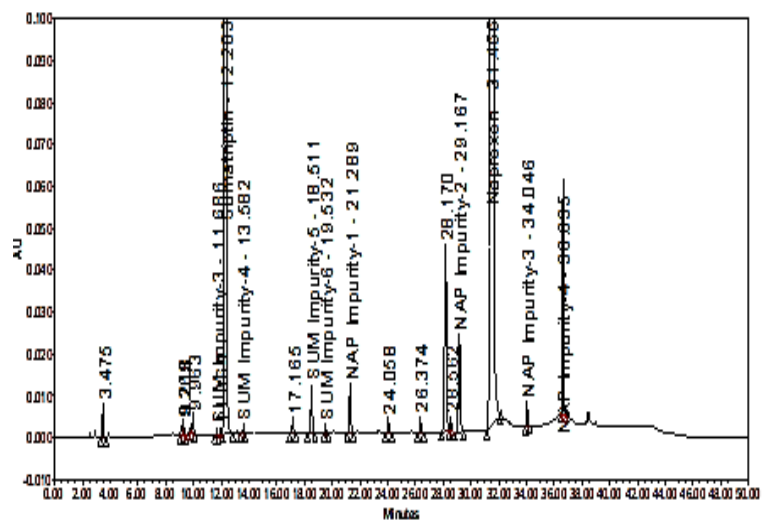

5e. Acid Stressed Sample

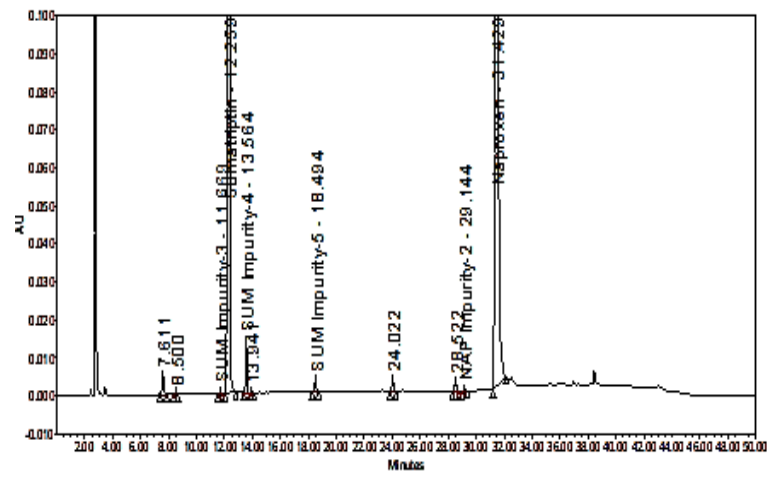

5g. Oxidation Stressed Sample

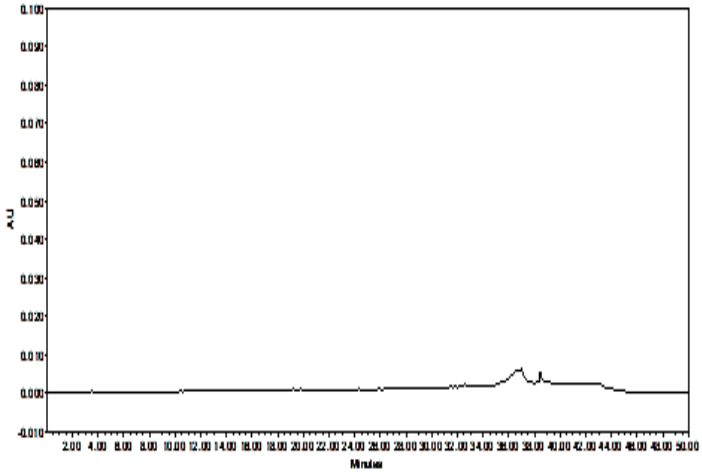

5b. Placebo

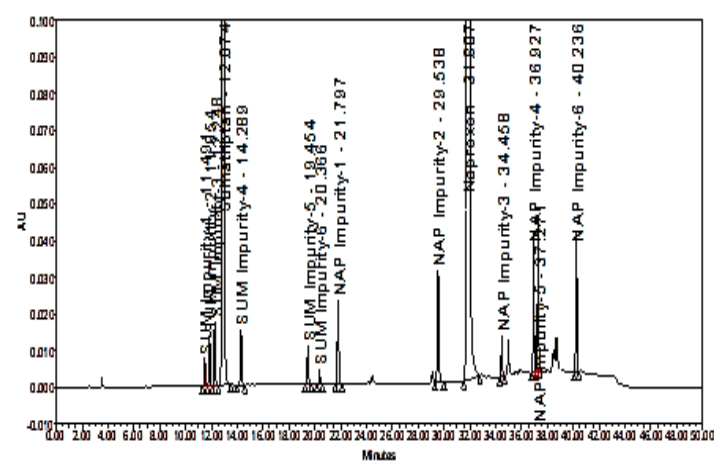

5d. Impurities Spiked Sample solution

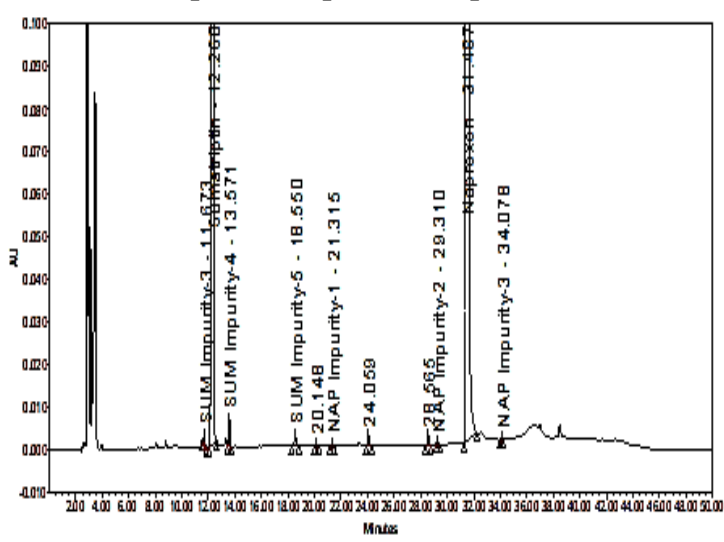

5f. Base Stressed Sample

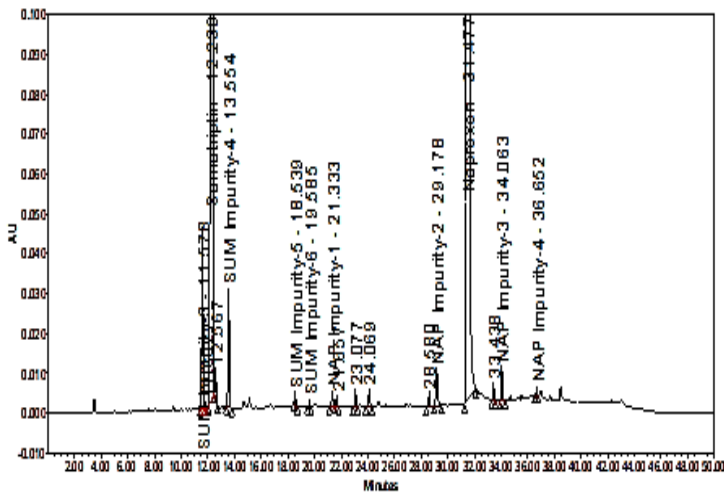

5h. Thermal Stressed Sample 


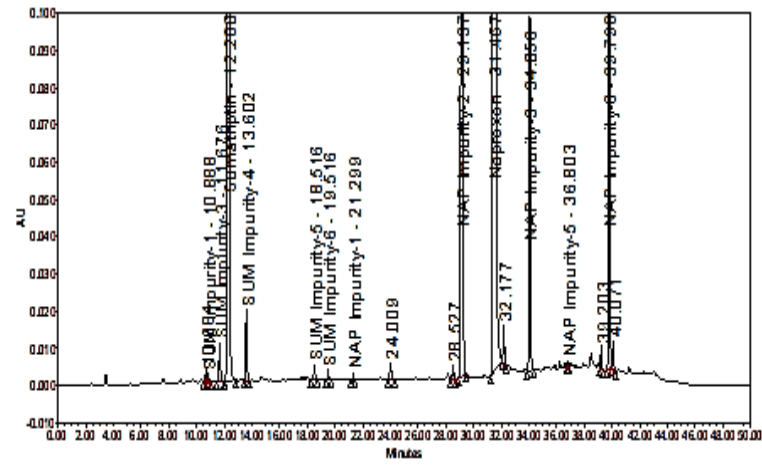

5i. Photolytic Stressed Sample

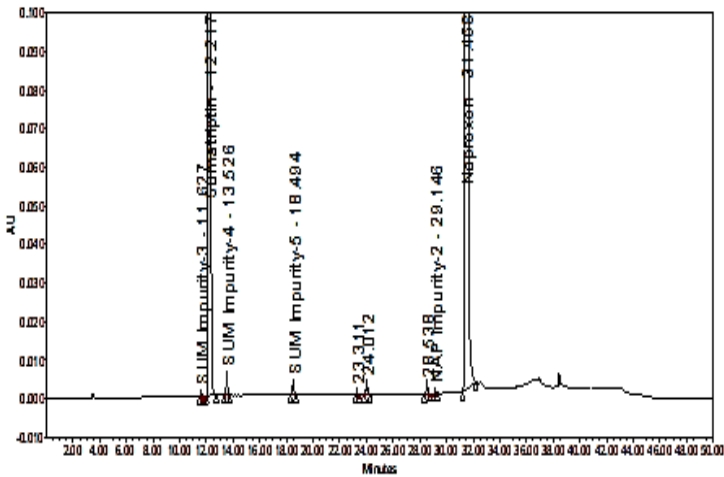

5j. Humidity Stressed Sample

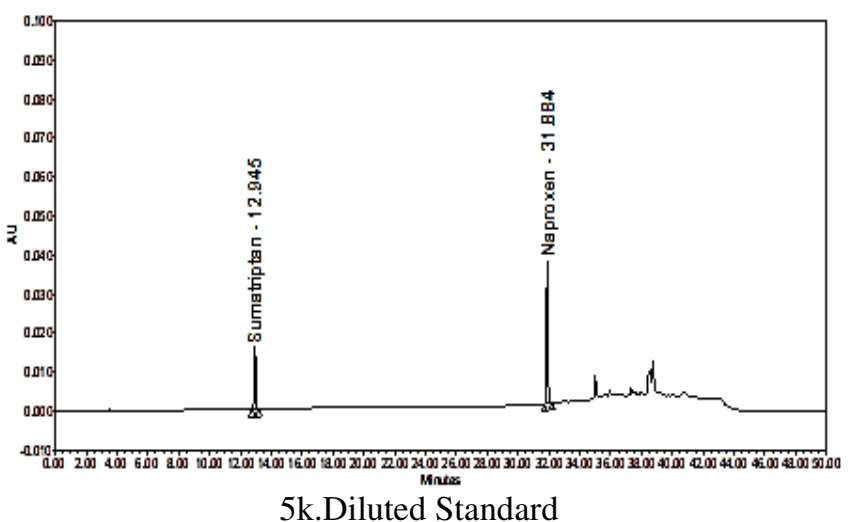

Fig.-5: Representative Chromatograms

\section{Thermal Stress Condition}

SUM shows increased values for SUM impurity 3 and SUM impurity 4. NAP shows slight increase in NAP impurity 2 and NAP impurity 3. No major unknown peaks are not generated either for SUM or NAP.

\section{Photolytic Stress Condition}

SUM shows an increase in values for SUM impurity 3 and SUM impurity $\sim$. Whereas NAP degraded significantly and observed NAP impurity 2, NAP impurity 3, and NAP impurity 6. There are no unknown peaks increased from SUM and NAP.

\section{Humidity Stress Condition}

SUM shows a slight increase in values for SUM impurity 4 and NAP are found stable. For comprehensive-stress degradation data refer to Table-4 and Fig.-5.

Table-4: Comprehensive Stress Degradation Data

\begin{tabular}{c|c|c|c|c}
\hline Stress parameter & $\begin{array}{c}\text { Exposure } \\
\text { interval }\end{array}$ & \multicolumn{2}{|c|}{$\%$ Degradation } & Major peaks observed \\
\cline { 3 - 4 } & 180 minutes & 1.94 & 2.90 & $\begin{array}{c}\text { SUM impurity 5, NAP } \\
\text { impurity } 1,2,4 \text { \& NAP } \\
\text { Unspecified }\end{array}$ \\
\hline $\begin{array}{c}\text { Acidic exposure }(1 \mathrm{M} \mathrm{HCl} / \\
\left.85^{\circ} \mathrm{C}\right)\end{array}$ & 180 minutes & 0.68 & 0.15 & SUM impurity 4 \\
\hline $\begin{array}{c}\text { Base exposure }(1 \mathrm{M} \mathrm{NaOH} / \\
\left.85^{\circ} \mathrm{C}\right)\end{array}$ & 60 minutes & 1.07 & 0.15 & SUM impurity 4 \\
\hline Oxidation $\left(5 \% \mathrm{H}_{2} \mathrm{O}_{2} / 60^{\circ} \mathrm{C}\right)$ & 120 hours & 3.81 & 0.72 & $\begin{array}{c}\text { SUM impurity 3 \& SUM } \\
\text { impurity 4, NAP } \\
\text { impurity 2 \& 3 }\end{array}$ \\
\hline Heat exposure $\left(105^{\circ} \mathrm{C}\right)$ & & &
\end{tabular}


RASĀYAN J. Chem.

Vol. 12 | No. 3 |1601 - 1612| July - September | 2019

\begin{tabular}{c|c|c|c|c}
\hline $\begin{array}{c}\text { Humidity } \\
\left(90 \% \text { Rel.Humidity @ } 25^{\circ} \mathrm{C}\right)\end{array}$ & 120 hours & 0.43 & 0.14 & SUM impurity 4 \\
\hline $\begin{array}{c}\text { Photolytic (10K Lux along with } \\
\text { UV 200 W.Hr.m }{ }^{-2} \text { ). }\end{array}$ & 7 days & 1.59 & 8.26 & $\begin{array}{c}\text { SUM impurity 3\&4, NAP } \\
\text { impurity 2,3 \& 6 }\end{array}$ \\
\hline
\end{tabular}

\section{Precision}

For precision along with intermediate precision (Ruggedness) data refer Table-5.

Table-5: Precision along with Ruggedness results

\begin{tabular}{c|c|c}
\hline Name of the component & $\begin{array}{c}\text { Method precision } \\
(\% \text { RSD })\end{array}$ & $\begin{array}{c}\text { Intermediate } \\
\text { precision (\%RSD) }\end{array}$ \\
\hline SUM impurity 1 & 0.5 & 0.5 \\
\hline SUM impurity 2 & 0.4 & 0.5 \\
\hline SUM impurity 3 & 0.2 & 0.4 \\
\hline SUM impurity 4 & 0.4 & 0.5 \\
\hline SUM impurity 5 & 2.9 & 4.1 \\
\hline SUM impurity 6 & 1.0 & 1.5 \\
\hline NAP impurity 1 & 0.2 & 0.7 \\
\hline NAP impurity 2 & 1.0 & 1.4 \\
\hline NAP impurity 3 & 0.8 & 0.4 \\
\hline NAP impurity 4 & 0.7 & 0.7 \\
\hline NAP impurity 5 & 2.0 & 1.1 \\
\hline NAP impurity 6 & 0.4 & 0.4 \\
\hline
\end{tabular}

\section{Sensitivity}

For LOD along with LOQ concentrations, refer Table-6.

Table-6: LOD Along with LOQ Values

\begin{tabular}{ccc}
\multicolumn{2}{c}{ Table-6: LOD Along with LOQ Values } \\
\hline Name of the component & $\begin{array}{c}\text { LOD values } \\
(\% \mathrm{w} / \mathrm{w})\end{array}$ & $\begin{array}{c}\text { LOQ values } \\
(\% \mathrm{w} / \mathrm{w})\end{array}$ \\
\hline SUM impurity 1 & 0.006 & 0.020 \\
\hline SUM impurity 2 & 0.008 & 0.025 \\
\hline SUM impurity 3 & 0.008 & 0.026 \\
\hline SUM impurity 4 & 0.008 & 0.026 \\
\hline SUM impurity 5 & 0.007 & 0.024 \\
\hline SUM impurity 6 & 0.006 & 0.021 \\
\hline SUM & 0.008 & 0.026 \\
\hline NAP impurity 1 & 0.0006 & 0.002 \\
\hline NAP impurity 2 & 0.0006 & 0.002 \\
\hline NAP impurity 3 & 0.0006 & 0.002 \\
\hline NAP impurity 4 & 0.0015 & 0.005 \\
\hline NAP impurity 5 & 0.0006 & 0.002 \\
\hline NAP impurity 6 & 0.0006 & 0.002 \\
\hline NAP & 0.0006 & 0.002 \\
\hline
\end{tabular}

\section{Linearity and Range}

The values observed for linearity data shows that each impurity has shown a linear relationship from proposed LOQ concentration to $150 \%$ of the proposed limit of the specification. Coefficient of correlation is found to be more than 0.995 for all impurities. For data refer Table-7a and Table- $7 \mathrm{~b}$.

Table-7a: Linearity Table for Sumatriptan Related Impurities

\begin{tabular}{c|c|c|c|c|c}
\hline $\begin{array}{c}\text { Name of the } \\
\text { constituent }\end{array}$ & $\begin{array}{c}\text { Regression line } \\
\text { equation }\end{array}$ & Linear Range(r) & $\begin{array}{c}\text { Coefficient of } \\
\text { Correlation }\end{array}$ & $\begin{array}{c}\mathrm{y}- \\
\text { intercept }\end{array}$ & $\begin{array}{c}\text { STEY } \\
\mathrm{X}\end{array}$ \\
\hline SUM impurity $\sim 1$ & $\mathrm{y}=10207 \mathrm{x}-348$ & $0.043-0.639$ & 0.99933 & -348 & 1011 \\
\hline SUM impurity 2 & $\mathrm{y}=78605 \mathrm{x}-176$ & $0.053-1.603$ & 0.99938 & -176 & 1917 \\
\hline SUM impurity 3 & $\mathrm{y}=106496 \mathrm{x}-218$ & $0.054-1.580$ & 0.99941 & -218 & 2502 \\
\hline SUM & $\mathrm{y}=96435 \mathrm{x}-251$ & $0.055-1.606$ & 0.99936 & -251 & 2390 \\
\hline SUM impurity 4 & $\mathrm{y}=90701 \mathrm{x}-263$ & $0.055-1.570$ & 0.99938 & -263 & 2167 \\
\hline
\end{tabular}


RASĀYAN J. Chem.

Vol. 12 | No. 3 |1601 - 1612| July - September | 2019

\begin{tabular}{c|c|c|c|c|c}
\hline SUM impurity 5 & $\mathrm{y}=63047 \mathrm{x}-412$ & $0.052-1.594$ & 0.99945 & -412 & 1437 \\
\hline SUM impurity 6 & $\mathrm{y}=73850 \mathrm{x}+133$ & $0.044-0.636$ & 0.99912 & 133 & 833 \\
\hline \multicolumn{7}{|c}{} \\
\hline $\begin{array}{c}\text { Name of the } \\
\text { constituent }\end{array}$ & Rable-7b: Linearity Table for Naproxen Sodium Related Impurities \\
\hline NAP impurity 1 & $\mathrm{y}=142230 \mathrm{x}-307$ & $0.026-1.908$ & 0.99941 & -307 & 4079 \\
\hline NAP impurity 2 & $\mathrm{y}=213904 \mathrm{x}-2827$ & $0.026-1.889$ & 0.99946 & -2827 & 5813 \\
\hline NAP & $\mathrm{y}=173127 \mathrm{x}+13333$ & $0.027-1.910$ & 0.99724 & 13333 & 10759 \\
\hline NAP impurity 3 & $\mathrm{y}=52194 \mathrm{x}-191$ & $0.063-1.886$ & 0.99936 & -191 & 1495 \\
\hline NAP impurity 4 & $\mathrm{y}=163290 \mathrm{x}-447$ & $0.026-1.842$ & 0.99939 & -447 & 4591 \\
\hline NAP impurity 5 & $\mathrm{y}=1749479 \mathrm{x}+6893$ & $0.024-1.872$ & 0.99921 & 6893 & 5844 \\
\hline NAP impurity $\sim 6$ & $\mathrm{y}=201718 \mathrm{x}-366$ & $0.024-1.898$ & 0.99941 & -366 & 5771 \\
\hline
\end{tabular}

\section{Accuracy}

Accuracy results indicate satisfactory recovery for each impurity ranges from LOQ to $150 \%$ level. Values are found to be in the range of 90 to $110 \%$ with $<5.0 \%$ RSD in triplicate data in each concentration. For data refer Table- $8 \mathrm{a}$, Table-8b, and Table-8c and Table- $8 \mathrm{~d}$.

Table-8a: Accuracy Values of SUM Impurities

\begin{tabular}{|c|c|c|c|c|c|c|c|c|c|}
\hline \multirow[b]{2}{*}{$\begin{array}{c}\text { Spiked } \\
\text { level }\end{array}$} & \multicolumn{2}{|c|}{ SUM impurity $\sim 1$} & \multirow[b]{2}{*}{$\begin{array}{c}\% \\
\text { Recove } \\
\text { ry }\end{array}$} & \multicolumn{2}{|c|}{ SUM impurity 2 } & \multirow[b]{2}{*}{$\begin{array}{c}\% \\
\text { Reco } \\
\text { very }\end{array}$} & \multicolumn{2}{|c|}{ SUM impurity 3 } & \multirow[b]{2}{*}{$\begin{array}{c}\% \\
\text { Reco } \\
\text { very }\end{array}$} \\
\hline & $\%$ Spiked & $\%$ Obtained & & $\begin{array}{c}\text { \%Spike } \\
\text { d }\end{array}$ & $\%$ Obtained & & $\%$ Spiked & $\%$ Obtained & \\
\hline LOQ 1 & 0.043 & 0.045 & 103.4 & 0.053 & 0.055 & 102.3 & 0.054 & 0.055 & 101.1 \\
\hline LOQ 2 & 0.043 & 0.044 & 102.3 & 0.053 & 0.054 & 100.6 & 0.054 & 0.054 & 98.6 \\
\hline LOQ 3 & 0.043 & 0.046 & 105.1 & 0.053 & 0.057 & 106.0 & 0.054 & 0.058 & 105.6 \\
\hline $50 \% \sim 1$ & 0.213 & 0.210 & 98.5 & 0.534 & 0.536 & 100.3 & 0.527 & 0.519 & 98.6 \\
\hline $50 \% \sim 2$ & 0.213 & 0.211 & 98.9 & 0.534 & 0.536 & 100.3 & 0.527 & 0.522 & 99.2 \\
\hline $50 \% \sim 3$ & 0.213 & 0.211 & 99.1 & 0.534 & 0.541 & 101.3 & 0.527 & 0.525 & 99.7 \\
\hline $100 \% \sim 1$ & 0.426 & 0.424 & 99.5 & 1.069 & 1.074 & 100.4 & 1.053 & 1.048 & 99.4 \\
\hline $100 \% \sim 2$ & 0.426 & 0.425 & 99.7 & 1.069 & 1.076 & 100.6 & 1.053 & 1.050 & 99.6 \\
\hline $100 \% \sim 3$ & 0.426 & 0.423 & 99.4 & 1.069 & 1.070 & 100.1 & 1.053 & 1.047 & 99.4 \\
\hline $150 \% \sim 1$ & 0.639 & 0.635 & 99.3 & 1.603 & 1.600 & 99.8 & 1.580 & 1.563 & 98.9 \\
\hline $150 \% \sim 2$ & 0.639 & 0.626 & 98.0 & 1.603 & 1.580 & 98.5 & 1.580 & 1.546 & 97.8 \\
\hline $150 \% \sim 3$ & 0.639 & 0.636 & 99.5 & 1.603 & 1.605 & 100.1 & 1.580 & 1.569 & 99.3 \\
\hline
\end{tabular}

Table-8b: Accuracy Values of SUM Impurities

\begin{tabular}{|c|c|c|c|c|c|c|c|c|c|}
\hline \multirow[b]{2}{*}{ Spiked level } & \multicolumn{2}{|c|}{ SUM impurity 4} & \multirow{2}{*}{$\begin{array}{c}\% \\
\text { Recover } \\
y\end{array}$} & \multicolumn{2}{|c|}{ SUM impurity 5 } & \multirow{2}{*}{$\begin{array}{c}\% \\
\text { Recove } \\
\text { ry }\end{array}$} & \multicolumn{2}{|c|}{ SUM impurity $\sim 6$} & \multirow{2}{*}{$\begin{array}{c}\% \\
\text { Recove } \\
\text { ry }\end{array}$} \\
\hline & $\begin{array}{c}\% \text { Spik } \\
\text { ed }\end{array}$ & $\begin{array}{c}\text { \%Obtain } \\
\text { ed }\end{array}$ & & $\%$ Spiked & $\begin{array}{c}\% \text { Obtai } \\
\text { ned }\end{array}$ & & $\begin{array}{c}\text { \%Spik } \\
\text { ed }\end{array}$ & $\begin{array}{c}\% \text { Obtai } \\
\text { ned }\end{array}$ & \\
\hline LOQ 1 & 0.055 & 0.055 & 100.1 & 0.052 & 0.050 & 96.8 & 0.044 & 0.043 & 98.5 \\
\hline LOQ 2 & 0.055 & 0.053 & 97.5 & 0.052 & 0.051 & 98.6 & 0.044 & 0.041 & 94.5 \\
\hline LOQ 3 & 0.055 & 0.052 & 94.6 & 0.052 & 0.055 & 106.7 & 0.044 & 0.043 & 97.6 \\
\hline $50 \% \sim 1$ & 0.523 & 0.484 & 92.4 & 0.531 & 0.493 & 92.8 & 0.219 & 0.202 & 92.4 \\
\hline $50 \% \sim 2$ & 0.523 & 0.485 & 92.7 & 0.531 & 0.510 & 95.9 & 0.219 & 0.205 & 93.7 \\
\hline $50 \% \sim 3$ & 0.523 & 0.491 & 93.8 & 0.531 & 0.526 & 99.1 & 0.219 & 0.206 & 94.4 \\
\hline $100 \% \sim 1$ & 1.047 & 1.073 & 102.5 & 1.063 & 1.038 & 97.7 & 0.437 & 0.418 & 95.7 \\
\hline $100 \% \sim 2$ & 1.047 & 1.073 & 102.5 & 1.063 & 1.054 & 99.2 & 0.437 & 0.404 & 92.4 \\
\hline $100 \% \sim 3$ & 1.047 & 1.067 & 101.9 & 1.063 & 0.972 & 91.4 & 0.437 & 0.407 & 93.0 \\
\hline $150 \% \sim 1$ & 1.570 & 1.606 & 102.3 & 1.594 & 1.492 & 93.6 & 0.656 & 0.606 & 92.4 \\
\hline $150 \% \sim 2$ & 1.570 & 1.574 & 100.2 & 1.594 & 1.471 & 92.3 & 0.656 & 0.620 & 94.6 \\
\hline $150 \% \sim 3$ & 1.570 & 1.609 & 102.4 & 1.594 & 1.492 & 93.6 & 0.656 & 0.635 & 96.8 \\
\hline
\end{tabular}

Table-8c: Accuracy Values of NAP Impurities

1610 
RASĀYAN J. Chem.

Vol. 12 | No. 3 |1601 - 1612| July - September | 2019

\begin{tabular}{|c|c|c|c|c|c|c|c|c|c|}
\hline \multirow[b]{2}{*}{ Spiked Level } & \multicolumn{2}{|c|}{ NAP impurity 1 } & \multirow{2}{*}{$\begin{array}{c}\% \\
\text { Recove } \\
\text { ry }\end{array}$} & \multicolumn{2}{|c|}{ NAP impurity 2} & \multirow{2}{*}{$\begin{array}{c}\% \\
\text { Recov } \\
\text { ery }\end{array}$} & \multicolumn{2}{|c|}{ NAP impurity 3} & \multirow{2}{*}{$\begin{array}{c}\% \\
\text { Recove } \\
y\end{array}$} \\
\hline & $\%$ Spiked & $\begin{array}{c}\text { \%Obta } \\
\text { ined }\end{array}$ & & $\begin{array}{c}\text { \%Spike } \\
\text { d }\end{array}$ & $\%$ Obtained & & $\begin{array}{c}\text { \%Spike } \\
\text { d }\end{array}$ & $\begin{array}{c}\text { \%Obtai } \\
\text { ned }\end{array}$ & \\
\hline LOQ 1 & 0.026 & 0.024 & 103.7 & 0.026 & 0.028 & 104.8 & 0.063 & 0.064 & 102.0 \\
\hline LOQ 2 & 0.026 & 0.027 & 103.2 & 0.026 & 0.027 & 102.6 & 0.063 & 0.063 & 100.6 \\
\hline LOQ 3 & 0.026 & 0.027 & 102.1 & 0.026 & 0.027 & 103.3 & 0.063 & 0.065 & 103.5 \\
\hline $50 \% \sim 1$ & 0.636 & 0.637 & 100.2 & 0.636 & 0.611 & 96.0 & 0.629 & 0.638 & 101.6 \\
\hline $50 \% \sim 2$ & 0.636 & 0.634 & 99.7 & 0.636 & 0.610 & 95.9 & 0.629 & 0.648 & 103.1 \\
\hline $50 \% \sim 3$ & 0.636 & 0.638 & 100.3 & 0.636 & 0.615 & 96.7 & 0.629 & 0.656 & 104.3 \\
\hline $100 \% \sim 1$ & 1.272 & 1.275 & 100.2 & 1.272 & 1.269 & 99.8 & 1.257 & 1.286 & 102.3 \\
\hline $100 \% \sim 2$ & 1.272 & 1.277 & 100.4 & 1.272 & 1.272 & 100.0 & 1.257 & 1.292 & 102.8 \\
\hline $100 \% \sim 3$ & 1.272 & 1.272 & 100.0 & 1.272 & 1.267 & 99.6 & 1.257 & 1.287 & 102.4 \\
\hline $150 \% \sim 1$ & 1.908 & 1.922 & 100.8 & 1.908 & 1.876 & 98.3 & 1.886 & 1.904 & 101.0 \\
\hline $150 \% \sim 2$ & 1.908 & 1.881 & 98.6 & 1.908 & 1.841 & 96.5 & 1.886 & 1.892 & 100.3 \\
\hline $150 \% \sim 3$ & 1.908 & 1.926 & 101.0 & 1.908 & 1.882 & 98.7 & 1.886 & 1.917 & 101.7 \\
\hline
\end{tabular}

Table-8d: Accuracy Values of NAP Impurities

\begin{tabular}{|c|c|c|c|c|c|c|c|c|c|}
\hline \multirow[b]{2}{*}{ Spiked Level } & \multicolumn{2}{|c|}{ NAP impurity 4 } & \multirow{2}{*}{$\begin{array}{c}\% \\
\text { Recove } \\
\text { ry }\end{array}$} & \multicolumn{2}{|c|}{ NAP impurity 5} & \multirow{2}{*}{$\begin{array}{c}\% \\
\text { Recove } \\
\text { ry }\end{array}$} & \multicolumn{2}{|c|}{ NAP impurity 6} & \multirow{2}{*}{$\begin{array}{c}\% \\
\text { Recove } \\
\text { ry }\end{array}$} \\
\hline & $\begin{array}{c}\text { \%Spike } \\
\text { d }\end{array}$ & $\begin{array}{c}\% \text { Obtai } \\
\text { ned }\end{array}$ & & $\begin{array}{c}\text { \%Spike } \\
\text { d }\end{array}$ & $\begin{array}{c}\% \text { Obtai } \\
\text { ned }\end{array}$ & & $\begin{array}{c}\% \text { Spike } \\
\text { d }\end{array}$ & $\begin{array}{c}\% \text { Obtai } \\
\text { ned }\end{array}$ & \\
\hline LOQ 1 & 0.026 & 0.024 & 91.7 & 0.024 & 0.024 & 100.9 & 0.024 & 0.022 & 90.6 \\
\hline LOQ 2 & 0.026 & 0.024 & 92.9 & 0.024 & 0.023 & 95.4 & 0.024 & 0.022 & 92.5 \\
\hline LOQ 3 & 0.026 & 0.025 & 93.7 & 0.024 & 0.023 & 96.6 & 0.024 & 0.023 & 95.4 \\
\hline $50 \% \sim 1$ & 0.614 & 0.597 & 97.1 & 0.624 & 0.576 & 92.3 & 0.633 & 0.603 & 95.3 \\
\hline $50 \% \sim 2$ & 0.614 & 0.605 & 98.5 & 0.624 & 0.566 & 90.8 & 0.633 & 0.618 & 97.6 \\
\hline $50 \% \sim 3$ & 0.614 & 0.611 & 99.5 & 0.624 & 0.579 & 92.9 & 0.633 & 0.623 & 98.5 \\
\hline $100 \% \sim 1$ & 1.228 & 1.228 & 100.0 & 1.248 & 1.220 & 97.8 & 1.265 & 1.257 & 99.4 \\
\hline $100 \% \sim 2$ & 1.228 & 1.230 & 100.1 & 1.248 & 1.226 & 98.2 & 1.265 & 1.261 & 99.7 \\
\hline $100 \% \sim 3$ & 1.228 & 1.219 & 99.2 & 1.248 & 1.246 & 99.9 & 1.265 & 1.257 & 99.3 \\
\hline $150 \% \sim 1$ & 1.842 & 1.815 & 98.5 & 1.872 & 1.810 & 96.7 & 1.898 & 1.838 & 96.8 \\
\hline $150 \% \sim 2$ & 1.842 & 1.817 & 98.6 & 1.872 & 1.822 & 97.3 & 1.898 & 1.871 & 98.6 \\
\hline $150 \% \sim 3$ & 1.842 & 1.837 & 99.7 & 1.872 & 1.826 & 97.6 & 1.898 & 1.873 & 98.7 \\
\hline
\end{tabular}

Solution Stability

Standard and sample solutions were injected for about 44 hours on periodical intervals at room temperature. SUM and NAP impurities did not show any increase in trend and nor detected any additional peaks. Hence it can be concluded that both standards along with sample solutions are found stable for about 44 hours at $25^{\circ} \mathrm{C}$.

\section{Robustness}

Robustness data revealed that closely eluting peaks SUM impurity 1 and SUM impurity 2, SUM impurity 2 and SUM impurity 3, SUM impurity 3 and SUM peak shows resolution greater than 1.2 inflow and organic ratio conditions. The similar observation is seen even for NAP impurity 4 and NAP impurity $\sim$. Robustness data generated on remaining conditions shows satisfactory resolution for all closely eluting peaks and response is also found to be satisfactory for each impurity. Hence developed method can be claimed as robust.

\section{CONCLUSION}

Publication is available for estimation of SUM and NAP related impurities in presence of SUM and NAP drug substances, but not in tablet matrix. In general drug substance presence in placebo matrix may react and give unknown peaks during the shelf life of the product. The ability to quantify those unknown peaks is not specified in the publication. The developed method is appropriate for quantification of SUM and NAP related known and unknown impurities that originate from the life cycle of the combination drug 
product. The projected method is validated as per compendia recommendation as mentioned in ICH. Forced degradation data shows not only the product behavior stability and also presents specificity and selectivity of the method. All the probable impurities are well resolved at a satisfactory level, showing resolution more than 1.2 insensitive robustness conditions for closely eluting peaks. Selected quantification wavelength of $230 \mathrm{~nm}$ is found suitable for quantification purpose. Impurities show satisfactory responses and did not find any placebo interference at this working wavelength. Linearity data depicts a linear relationship with a coefficient of correlation greater than 0.99 . Accuracy results prove the extraction capability of the method in the proposed diluent. Hence method can be claimed as specific, selective, precise, stability demonstrating and suitable for quantification of impurities.

\section{ACKNOWLEDGMENT}

The author has highly obliged to Aurobindo Pharma Limited management (A Division of APL Research Centre, Hyderabad, India) for providing an opportunity to work on this project.

\section{REFERENCES}

1. K. Chaouki and R. Couch James, Drug Des. Devel Ther., 4, 9 (2010), DOI: 10.2147/DDDT.S8410

2. C. Catalina and T. Stewart, Expert. Rev. Neurothe., 8, 1289 (2008), DOI: $10.1586 / 14737175.8 .9 .1289$

3. K. Cady Roger, L. Diamond Merle, P. Diamond Michael, E. Ballard Jeanne, E. Lener Michelle, P. Dorner Deborah, J. Derosier Frederick, A. Mc.Donald Susan, W. Jonathan and R. Chris, Headache., 51, 664 (2011), DOI: 10.1111/j.1526-4610.2011.01894.x

4. R. Morrone, N. D. Antona and G. Nicolosi, Rasayan J. Chem., 1, 732 (2008).

5. P. Chanti Babu and K. Durga Prasadu., Rasayan J. Chem., 8, 67 (2015).

6. G. Riddhi and D. Abhay, Int. J. Pharm. Sci. Res., 2, 116 (2011), DOI:10.13040/IJPSR.09758232.2(1).116-20

7. M. Trinath, K. Banerjee Saurabh, D. Teja Hara Hari and C. Bonde, Der. Pharmacia Sinica.,1, 36 (2010).

8. M. Michael Adel, M. Lotfy Hayam, R. Reda Mamdouh, M. Karim, S. Vishwa, G. Siraki Arno, O. ElKadi, S. Ayman and A. Shehata Mostafa , Curr. Anal. Chem., 8, 512 (2012), DOI: $10.2174 / 157341112803216861$

9. Y. Swapna, G. Nagarjun Reddy and K.Sekhar Chandra, Int. J. Pharm.Biol.Sci., 3 ,179(2013).

10. K. Sujana, D. SankarGowri and K. Abbulu, Int. J. Pharm. Sci. Res., 3 , 3433 (2012). DOI: $10.22270 /$ jddt.v3i2.463

11. D. Solanki Sagar and U. Patel Paresh, Int. J. Pharm. Pharm. Sci., 4, 276 (2012).

12. A. Krishna, K. Kiranmai, Rojy George, K. Meenamaduri, R. Ravinder reddy and A.D. Panikumar, J. Pharm. Res., 4 , 3021 (2011).

13. R. Yarram Reddy, K. Kakumani Kumar, M.R.P Reddy and K. Mukkantti , J.Anal. Bio. Anal. Tech., 2, 2 (2011), DOI: 10.4172/2155-9872.1000121

14. R.P. Gondalia, A.P. Dharamsi, Asian. J. Pharm.Clin. Res., 4, 31 (2011).

15. R. PalavaiSripal, S. Shakil and H. Kishore Kumar, Asian J. Chem., 25, 9717(2013), DOI: 10.14233/ajchem.2013.15219

16. R. Palavai Sripal, S. Shakil, V. Gururaj, N. Mathivanan, V. Prasad Reddy and S. Jayapal, J. Chem Pharm. Res., 4 ,3263 (2012).

17. P.N. Patel, V.S. Karakam, G. Samanthula, and S. Ragampeta, J. Sep. Sci., 38, 3354(2015), DOI: $10.1002 /$ jssc. 201500343

18. Validation of Compendial Methods <1225>, The United States Pharmacopeia, (2012).

19. Photo stability Testing of New Drug Substances and Products, ICH, Q1B, (2005).

20. Analytical Procedures and Methods Validation, US FDA Guidance, (2000).

21. Validation of Analytical Procedures: Text and Methodology, ICH, Q2 (R1), (2005).

22. Stability Testing of New Drug Substances and Products, ICH, Q1A (R2), (2005).

[RJC-5183/2019] 